\title{
Radiological hazard in the sediment of the Xining section of the Huangshui River, China
}

\author{
X. Lu, S. Chao and X. Ding \\ School of Tourism and Environment, Shaanxi Normal University, Xi'an 710062, P.R. China.
}

Received 25 August 2015 - Accepted 27 October 2015

\begin{abstract}
Natural radioactivity was determined in sediment samples collected from the Xining section of the Huangshui River in northwest China. The activity concentrations of ${ }^{226} \mathrm{Ra},{ }^{232} \mathrm{Th}$ and ${ }^{40} \mathrm{~K}$ in the sediment samples range from 15.8 to $65.3,24.3$ to 86.0 and 432.6 to $702.4 \mathrm{~Bq} \cdot \mathrm{kg}^{-1}$ with an average of $32.4,43.0$ and $527.5 \mathrm{~Bq} \cdot \mathrm{kg}^{-1}$, respectively. All investigated sediment samples have radium equivalent activity lower than the limit of $370 \mathrm{~Bq} \cdot \mathrm{kg}^{-1}$ and an external hazard index less than unity. The mean outdoor air absorbed dose rate is $63.5 \mathrm{nGy} \cdot \mathrm{h}^{-1}$ and the corresponding outdoor annual effective dose rate is $0.078 \mathrm{mSv} \cdot \mathrm{y}^{-1}$. The radiation level of the studied location is safe, and the sediment can be safely used in construction according to the current norms.
\end{abstract}

Keywords: radionuclide / gamma-ray spectrometry / radiation hazard / gamma dose rate / sediment

\section{Introduction}

Natural radionuclides, i.e. uranium and thorium series radioisotopes and natural ${ }^{40} \mathrm{~K}$, have been components of the Earth since its existence and widely exist in the Earth's crust, rocks, soils, sediments, plants, water and air (UNSCEAR, 2000). Natural radioactivity levels of river sediments vary from place to place depending upon the concentration of ${ }^{226} \mathrm{Ra}$, ${ }^{232} \mathrm{Th}$ and ${ }^{40} \mathrm{~K}$ present in rock and soil (Qureshi et al., 2014). Moreover, some agricultural activities (e.g. phosphate fertilizer usage) and industrial activities (e.g. phosphate fertilizer manufacture, coal-fired power plants and cement production) in the river valley may affect the natural radioactivity level of the river sediment.

Natural radioactivity and the associated radiation hazard of river sediment have been determined and widely reported in the literature by many authors (El-Gamal et al., 2007; Jibiri and Okeyode, 2011; Ramasamy et al., 2012; Saç et al., 2012; Qureshi et al., 2014) in recent decades, since river sediment is one of the most important mixing materials for building construction in many parts of the world. However, similar studies in Chinese rivers are limited. The Huangshui River is an important tributary upstream of the Yellow River. The mainstream area of the Huangshui River is the political, economic, cultural and transportation center of Qinghai province. The annual sediment load in the mainstream of the Huangshui River is $1.918 \times 10^{10} \mathrm{~kg}$, and its annual average erosion modulus is $1.25 \times 10^{6} \mathrm{~kg} . \mathrm{km}^{-2}$. The Huangshui River flows through Xining city from northwest to southeast and its environmental quality is influenced by the local anthropogenic activities,

\footnotetext{
* luxinwei@snnu.edu.cn
}

e.g. industrial discharge and domestic sewage, as well as urban surface runoff. The river sediments of the Xining section are generally dredged and are used as building materials. The present work investigated the activity concentrations of natural radionuclides in the sediment of the Xining section of the Huangshui River, China, using gamma-ray spectrometry, and assessed the radiation level of the study area and the radiation hazard risk of the sediment when it is used in the construction of dwellings.

\section{Materials and methods}

\subsection{Sample collection and preparation}

Thirty-five sediment samples were collected from the Xining section of the Huangshui River in Qinghai province, China (Figure 1), and were dried for about $24 \mathrm{~h}$ to a quality of basic stability by a freeze-drying machine and then flipped, crushed and sieved through a $1.0-\mathrm{mm}$ nylon sieve to remove stones, dead organisms and coarse debris before halving. Onehalf of the sieved sediment samples were dried at $110{ }^{\circ} \mathrm{C}$ for about 36-48 h in an oven, homogenized, ground and then sieved through a $0.16-\mathrm{mm}$ mesh. All sediment samples were sealed for about 30 days before counting so as to allow ${ }^{226} \mathrm{Ra}$ and ${ }^{224} \mathrm{Ra}$ to reach secular equilibrium with their decay products (Alencar and Freitas, 2005).

\subsection{Measurement of radioactivity}

The activity concentrations of ${ }^{226} \mathrm{Ra},{ }^{232} \mathrm{Th}$ and ${ }^{40} \mathrm{~K}$ in the samples were measured using a $3 \times 3$ in. $\mathrm{NaI}(\mathrm{Tl})$ gamma-ray 


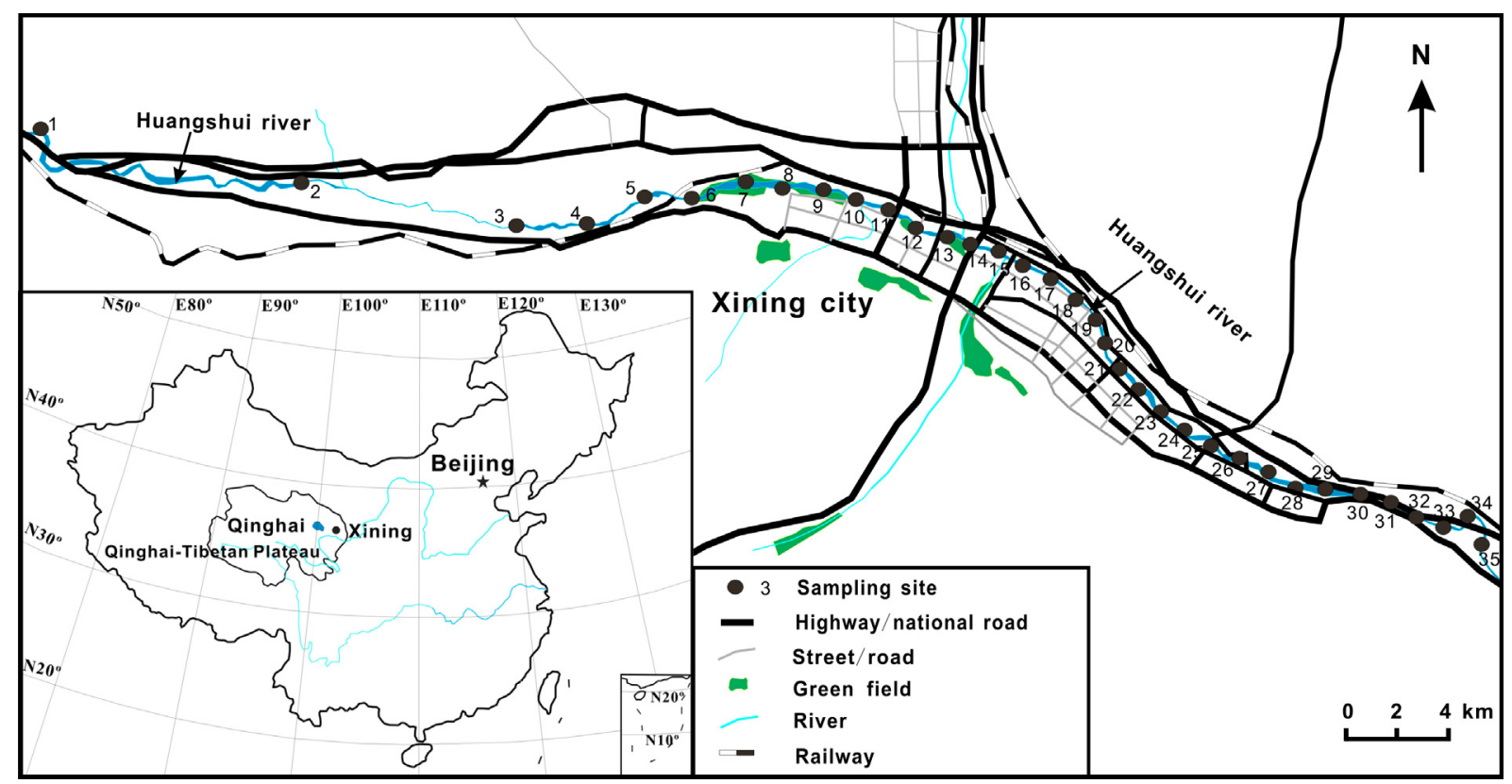

Figure 1. Sampling sites of sediment along the Xining section of the Huangshui River, China.

spectrometer with an energy resolution of about $8 \%$ at the $661.6 \mathrm{keV}$ peak of ${ }^{137} \mathrm{Cs}$ (Lu et al., 2014). The activity of ${ }^{232} \mathrm{Th}$ was determined through the photopeak of ${ }^{212} \mathrm{~Pb}$ at $238.6 \mathrm{keV}$ and ${ }^{208} \mathrm{Tl}$ at $2614 \mathrm{keV}$, whereas the activity of ${ }^{226} \mathrm{Ra}$ was measured by the photopeaks of ${ }^{214} \mathrm{Bi}$ at $609.3 \mathrm{keV}$ and $1764.5 \mathrm{keV}$ (El-Taher et al., 2010). The ${ }^{40} \mathrm{~K}$ activity was measured directly through its gamma-ray energy peak of $1460.8 \mathrm{keV}$. The measurement time of activity was $300 \mathrm{~min}$. Each sample was counted four times before an average was calculated.

\section{Results and discussion}

The activity concentrations of ${ }^{226} \mathrm{Ra},{ }^{232} \mathrm{Th}$ and ${ }^{40} \mathrm{~K}$ in the sediment from the Xining section of the Huangshui River are shown in Figure 2. The activity concentrations of ${ }^{226} \mathrm{Ra},{ }^{232} \mathrm{Th}$ and ${ }^{40} \mathrm{~K}$ in the samples range from 15.8 to $65.3,24.3$ to 86.0 and 432.6 to $702.4 \mathrm{~Bq} \cdot \mathrm{kg}^{-1}$ with an average of $32.4,43.0$ and $527.5 \mathrm{~Bq} \cdot \mathrm{kg}^{-1}$, respectively. ${ }^{40} \mathrm{~K}$ is the main contributor of the total activity concentration, which accounts for approximately $75 \%$ to $93 \%$ of the total activity concentration of the sediment samples from the Xining section of the Huangshui River. A significant positive correlation was observed between ${ }^{226} \mathrm{Ra}$ activity and ${ }^{232} \mathrm{Th}$ activity (Pearson correlation coefficient $R=0.843, P=0.000,2$-tailed test). Compared with the average activity concentration of local soil (Guo et al., 1994a), as well as Chinese soil and worldwide soil (UNSCEAR, 2000), the mean value of ${ }^{226} \mathrm{Ra}$ in the sediment is lower than the average of local soil (36.0 Bq. $\mathrm{kg}^{-1}$ ) and close to the average of Chinese soil (32 Bq. $\mathrm{kg}^{-1}$ ) and the worldwide populationweighted average for soil ( $32 \mathrm{~Bq} \cdot \mathrm{kg}^{-1}$ ), while the mean concentration of ${ }^{232} \mathrm{Th}$ in the sediment is close to the average of local soil (45.6 Bq. $\left.\mathrm{kg}^{-1}\right)$, Chinese soil (41 Bq. $\mathrm{kg}^{-1}$ ) and the worldwide population-weighted average for soil $\left(45 \mathrm{~Bq} \cdot \mathrm{kg}^{-1}\right)$. The mean concentration of ${ }^{40} \mathrm{~K}$ in the sediment samples is lower than the average of local soil (661.2 Bq. $\left.\mathrm{kg}^{-1}\right)$ and higher than the average of Chinese soil (440 Bq. $\mathrm{kg}^{-1}$ ) and worldwide soil $\left(420 \mathrm{~Bq} \cdot \mathrm{kg}^{-1}\right)$.

The radium equivalent activity, assuming that $370 \mathrm{~Bq} \cdot \mathrm{kg}^{-1}$ of ${ }^{226} \mathrm{Ra}, 259 \mathrm{~Bq} \cdot \mathrm{kg}^{-1}$ of ${ }^{232} \mathrm{Th}$ and $4810 \mathrm{~Bq} \cdot \mathrm{kg}^{-1}$ of ${ }^{40} \mathrm{~K}$ can produce the same gamma-ray dose (Beretka and Mathew, 1985), is a common radiological index to describe the radiation hazard from natural radionuclides in a material. In the investigated sediment samples, the radium equivalent activity ranges from 88.4 to $222.8 \mathrm{~Bq} \cdot \mathrm{kg}^{-1}$ with an average of $134.4 \mathrm{~Bq} \cdot \mathrm{kg}^{-1}$, which are lower than the internationally accepted value of $370 \mathrm{~Bq} \cdot \mathrm{kg}^{-1}$ (UNSCEAR, 2000). The external hazard index, a radiation index to describe the hazard to people of external gamma radiation from natural radionuclides in a material (Beretka and Mathew, 1985), in the sediment samples ranges from 0.24 to 0.60 with an average of 0.36 , which are less than unity.

The total absorbed gamma dose rate in outdoor air at $1 \mathrm{~m}$ above the ground (UNSCEAR, 2000) due to the activity concentrations of ${ }^{226} \mathrm{Ra},{ }^{232} \mathrm{Th}$ and ${ }^{40} \mathrm{~K}$ in the sediment is in the range of 42.7 to $102.3 \mathrm{nGy} \cdot \mathrm{h}^{-1}$ with a mean value of $63.5 \mathrm{nGy}^{-1} \mathrm{~h}^{-1}$, which is slightly higher than the population-weighted average value of global primordial radiation of 59 nGy.h ${ }^{-1}$ (UNSCEAR, 2000), and close to the average value of the natural gamma radiation dose rate of China (62.0 nGy.h ${ }^{-1}$ ) (UNSCEAR, 2000) and Qinghai (62.2 nGy.h ${ }^{-1}$ ) (Guo et al. 1994b). The corresponding outdoor annual effective dose rate due to gamma-ray emission from ${ }^{226} \mathrm{Ra},{ }^{232} \mathrm{Th}$ and ${ }^{40} \mathrm{~K}$ in the sediments ranges from 0.052 to $0.125 \mathrm{mSv} . \mathrm{y}^{-1}$ with an average of $0.078 \mathrm{mSv} . \mathrm{y}^{-1}$, which is close to the worldwide average value of $0.07 \mathrm{mSv}^{-1} \mathrm{y}^{-1}$ for the outdoor annual effective dose (UNSCEAR, 2000) and is about $7.8 \%$ of the $1 \mathrm{mSv} \cdot \mathrm{y}^{-1}$ recommended by the International Commission on Radiological Protection (ICRP, 1990) as the maximum annual dose to members of the public. 

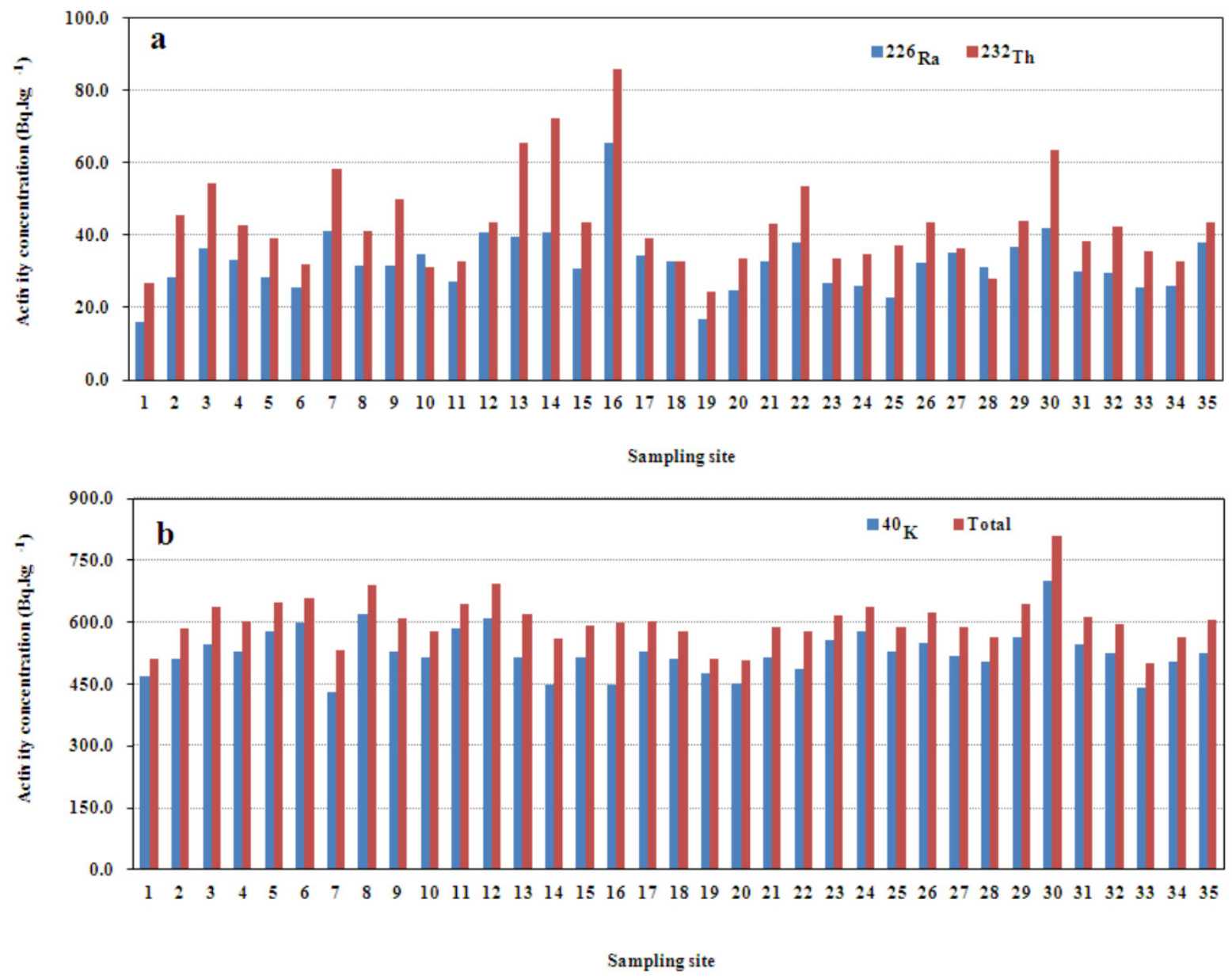

Figure 2. Activity concentration of natural radionuclides in the sediments.

\section{Conclusions}

The activity concentrations of ${ }^{226} \mathrm{Ra}$ in the sediment samples from the Xining section of the Huanghsui River, China, are lower than the average of local soil and close to the average of Chinese soil and worldwide soil. The ${ }^{232} \mathrm{Th}$ concentrations in the sediments are close to the average of local soil, Chinese soil and worldwide soil. The mean concentration of ${ }^{40} \mathrm{~K}$ in the sediment samples is less than the average of local soil and higher than the average of Chinese soil and worldwide soil. The radium equivalent activity values of all sediment samples are lower than the internationally accepted value of $370 \mathrm{~Bq} \cdot \mathrm{kg}^{-1}$ and the external hazard index values of all samples are less than unity. The results show that none of the studied locations was considered a radiological hazard area and the sediment can be safely used in construction based on the current knowledge and the current norms.

Acknowledgements. This research was supported by the National Natural Science Foundation of China through Grant 41271510 and the Fundamental Research Funds for the Central University through Grant GK 200901008. All experiments were carried out in the Environmental Science Lab of Shaanxi Normal University. We thank Long Pang, Tingting Feng and Ni Zhao for their help with the sample preparation. We also thank the Editor-in-Chief Prof. François Paquet and anonymous reviewers for their insightful suggestions and critical reviews of the manuscript.

\section{References}

Alencar A.S., Freitas A.C. (2005) Reference levels of natural radioactivity for the beach sands in a Brazilian southeastern coastal region, Radiat. Meas. 40, 76-83.

Beretka J., Mathew P.J. (1985) Natural radioactivity of Australian building materials, industrial wastes and by-products, Health Phys. 48, 87-95.

El-Gamal A., Nasr S., El-Taher A. (2007) Study of the spatial distribution of natural radioactivity in the upper Egypt Nile River sediments, Radiat. Meas. 42, 457-465.

El-Taher A., Makhluf S., Nossair A., Abdel Halim A.S. (2010) Assessment of natural radioactivity levels and radiation hazards due to cement industry, Appl. Radiat. Isotopes 68, 169-174.

Guo L., Wang X., Hu X., Cheng F., Wang T. (1994a) Investigation of natural radionuclide contents in soil in Qinghai province, Radiat. Prot. 14, 226-229 (in Chinese).

Guo L., Hu X., Cheng F., Wang X., Xing H. (1994b) Investigation of environmental natural penetrating radiation level in Qinghai province, Radiat. Prot. 14, 451-458 (in Chinese). 
ICRP Publication 60 (1990) Radiation protection: 1990 Recommendations of the international commission on radiological protection. Pergamon Press, Oxford.

Jibiri N.N., Okeyode I.C. (2011) Activity concentrations of natural radionuclides in the sediments of Ogun River, Southwestern Nigeria, Radiat. Prot. Dosim. 147, 555-564.

Lu X., Chao S., Yang F. (2014) Determination of natural radioactivity and associated radiation hazard in building materials used in Weinan, China, Radiat. Phys. Chem. 99, 62-67.

Qureshi A.A., Tariq S., Din K.U., Manzoor S., Calligaris C., Waheed A. (2014) Evaluation of excessive lifetime cancer risk due to natural radioactivity in the rivers sediments of Northern Pakistan, $J$. Radiat. Res. Appl. Sci. 7, 438-447.
Ramasamy V., Suresh G., Rajkumar P., Murugesan S., Mullainathan S., Meenakshisundaram V. (2012) Reassessment and comparison of natural radioactivity levels in relation to granulometric contents of recently excavated major river sediments, J. Radioanal. Nucl. Chem. 292, 381-393.

Saç M.M., Ortabuk F., Kumru M.N., İçhedef M., Sert Ş. (2012) Determination of radioactivity and heavy metals of Bakirçay river in Western Turkey, Appl. Radiat. Isotopes 70, 2494-2499.

UNSCEAR (2000) Sources and effects of ionizing radiation. United Nations Scientific Committee on Effects of Atomic Radiation. United Nations Publication, New York, USA (Report to the General Assembly with Scientific Annexes), 2000 Reports.

Cite this article as: X. Lu, S. Chao, X. Ding. Radiological hazard in the sediment of the Xining section of the Huangshui River, China. Radioprotection 51(1), 43-46 (2016). 